\title{
O NASCIMENTO DA PINTURA MODERNA
}

Marta Dantas *

\section{Resumo:}

A Histónia da Arte não é a hîstória das aplicaçäes progressivas de princípios estéticos, pelo

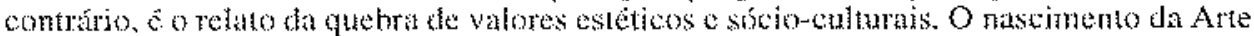
modema representa uma ruptura radical de valores estélicos que tiveram origem no Remascimento, $D$ que nos pemite considerar os acontecimentos ligados ao mundo das artes, na segunda thetade do século XIX, como uma "revoluçäo estética". Revolução esta que pôs fim ao imaginán coletivo, aos modelos de beleza, a concepçăo de mundo hierarguzado e fez enzergir uma percepgăo essencialmente individual.

\section{Palavras-Chave:}

Históriaz, bistória da arte história da cultura, estélica.

"Tanto quanro no passado, a arte hoje näo se revela como aplicaçäo progressiva de um principio."

Pierre Francastel

A importancia de estudarmos as origens da pintura moderna está, entre outras coisas, no fato de a Historia da Arte não ser a historia de aplicações progressivas de princípios estéticos mas, pelo contrírio, em vários momentos ela é o relato da quebra de valores estéticos e sócio-culturais.

O nascimento da pintura modema é umn marco importante na história da cultura ocidental, porque ele representa una nuptura radical de uma estética e de valores que tiveram origem no Renascimento. Essa "revolução estética" ocorreu na segunda metade do século XIX.

Antes, porém, falaremos de uma primeira ruptura na História da Arte anterior a que deu onigem a pintura moderna, aquela que separa a arte medieval da arte renascentista. Essa primeira cisão começa quando a pintura se toma independente

\footnotetext{
* Meste sm Nistória pela UNESP - Assis/SP e Professora de Historia da Arte, do Departatnento de Ciencials Fumatras e Sociats da LIN]ARA.
} 
da arquiteturit. quando ela passa a ter o seu proprio suportc (a tela). Soma-se ao aparecimento do stppore a descoberta dit tintal áleo pelos flamengos. A arte deixa

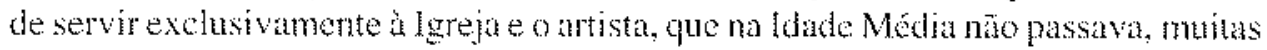
vezes, de un atesajo desconherido sai do anonimato passa a ser figura requisitada nas cones dos monarcas. Surge um novo personagem nocenario históno-omecenas: burgues monarca on principe que finmelava protegia os artistats. O aprendizado ocorre atraves da relkyäo enre mestre e discípulo: assistimos a fim das corporaços de oficio medievais.

Como advento do Renascimento a arte passou a solrer inluências do espirito

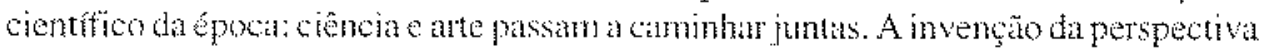
nutamática pelo arquiteto florentino Filipo Bnonelleschi e o seu aperfeiçomento pelo arquiteto Leon Batista Alberti - a perspectiva linear - pernitiu ao espaço, que antes ara representado pela justaposiço de imargens, ser representado de forma racional. criando a ilusāo de profundidade e dando aos objetos e a natureza retratada uma aparencia natual. Os jogos do luz e sombra ("sfumato") permitiram criar a ilusăo de volume (privilegro ate entào da esculura dos revos). Oestudo da anatomia contribuin patra desento idealizado do corpo humano. A representacia deste en relacionada a certas leis. consideradas absolutas, do universo - a dontrina do macrocosmo-microcosno -... que afimmas a que um microcosmo sempre representa a ordem do makrocosmo; logo, acreditava-se gue a proporça do corpo humano refledia a ordem do universo. Essa idén resistrada no "Tratado de Desenho" de Leonardo Da Vinci persistu durme 250 anos nos Tratados de Belas Ates e Arquitatura.

O antropocentrismo levou o homem do século XV até meados do século XIX at uma revalorizaño da estética greco-roman e dar feora aristotelica da arte. Esta última alimava ser a funcio da arte nä somente reproduzir a natureza mas apreender sua verdade ideal. Apesa do surgimento de movimentos que reagiam ao espínto racionaltita e cientifico do Renascimento - o Maneirsmo e Barroco - ar fe na razio e na cî́ncia. a crença de que o verdadeiro é o natumal e o natural é o tacional. predominou.

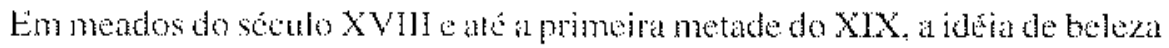
continuava dietamente ligada à idéia de simetria (proporçăo): a aplicaça rigida desta levon ito academicismo da forma e. por isso, a at vidade do pintor passon a ser guiada por manuits (particulamente o de athoria de Joham Winckelmann e regras estilisticas. estudadas nas academias e que tinham como base a ate classica e renasentista. Porano, wa consideralo bom pintor noro aquele que criava formas mas sim o que dominava com maestria as tecnicas do desenho. as receitas descritas nos mamuas. A técnica, más uma vez, se sobrepunha ì criatividade e a imatrinaçio do homem e. consequentemerte, odesenth erat valorizado em detrimento da cor Os temas considerados "dignos" pela pintura eram mato ponco variados: temas religiosos. míológions, históricos ou retratos. pos nấ podemos esquecer que desde o Renascimento a burguesia deixava-se retratar para guardar para a posteridade sua 
imagem.

As escavaçồes es estudos arqueológicos feitos em Pompéin e Herculano duas cidades romanas destruidas pela erupeăo do Vesívio - entre os anos de $1738 \mathrm{e}$ 1780 , trouxeram à tona ornamentos, decoraçöes e aspectos da vida cotidiana, permitindo aos pintores transporem para as saas telas detathes do mundo clássico e uma melhor dếniç̧̇io acerca do conceito de "clássico". A Itália se tornava, novamente, o centro artístico por excelencia; lá ocorria o maior concurso de pinturi - o "Prix de Rome" - ambição máxima dos pintores da época.

Esse movimento, que nasceu como reaçäo ao "mau gosto" da estética barroca e como herdeira dos valores estéticos renascentistas e clássicos, foi denominado Neoclassicismo ou Academicismo. O sea caráter decorativo, a ausência de senlintentos e de fantasias, decorre tanto dos rígidos códigos de normas e fómulas plásticas, nas quais essa pintura se baseava, quanto de sua preocupação com a satisfaçäo intelectual elogica.

Mas esses valores estéticos tão rígidos herdados do Classicismo e do Renascimento, que não permitiam ao artista expor a sua individualidade, tenderam a desaparecer, visto que a modemidade näo comporłava mais essa concepęa de mundo tão fechada, imutável, estática, organizada, rígida e jdealizada; concepção esta que, segundo Pierre Francastel, revela mais os poderes da trudição medieval do que forças inovadoras. Essa nova ruptura deu ongem ao que chamamos de pintura moderna. $O$ homem näo reflete mais o macrocosmo; o mundo năo é mais estável nem imóvel e muito menos finito. Uma nova arte começa a ser elaborada em funçắo de uma concepção dinâmica do mundo e dis coisas.

Segundo o historiador da arte Giulio Carlo Argan (1993), a natureza, a partir da segunda metade do século XIX. "nâo é mais a ordem revelada e imutável da criação ... năo é mais o modelo universal, mas um eslímulo a que cada um reage de modo diferente; mổ trais a lonte de todo o saber, mas o objeto da pesquisa cognitiva". A arte afirma assim a sua autonomia e o artista não se abstrai da realidade histórica: agora ele se declara querer ser de seu próprio tempo.

Mas e se tivessemos que precisar uma dati ou um acontecinzento que marcasse o inicio da pintura moderna e, portanto, o momento de ruptua entre a tradição e o que estaria por vir? Sem dúvida, esta nảo é uma pergunta fácil de responder, pois os historiadores da arte năo sầo unanimes, näo hă un consenso e, muitas vezes, suas opintöes stio divergentes. O interessante, porém, é confrontar a opinião dos especialistas.

Para o historiador da arte E. Gombrich, o terreno da tradição européia no campo da arte vai cedendo pouco a ponco. O advento da Revoluçïo Francesa sm 1789 fez eclodir espiritos libertános e rebeldes que não se satisfaziam em pintar cenas de um mundo e de um imaginário distante, no termpo no espaço. Aqqueles temas tradicionats parecian ser atgora sem sentido para muilos artistas. O centro de difusão e discussāo artística se desloca, então, de Roma para a França. 
Os ventos da revolução burguesa fizeram com que alguns artislas sentissem estar vivendo em tempos heróicos; os pintores ligados ao movimento revolucionátio pastaram a registrar os grandes acontecimentos do seu tempo, pois acreditavam ser estes täo dignos quanto os episódios da história grega ou fomana. Jacques Louis David (1748-1825) foi o maior representante dessa pintura neoclásica histórica e sua obra A morte de Marat, que data de 1793, ilustra de forma exemplar a transformação do mátir revolucionário em herói do povo. Como eximio pintor neoclássico, a obra de David é impregnada de conhecimentos acadêmicos; os músculos do corpo de Mara, por exemplo, são modelados com a precisão da escultura grega e romuna, a aparência é de uma beleza nobre, contudo, o ideal clássico não é para ele inspiração poética, é modelo ético. Há total ausência de emoça, pois David năo comenta o fato, apresenta-o. Todavia, a pintura neoclássica năo era a expressão da individualidade do artista. Esta, segundo E. Gombrich(1988), só se fazia incidentalmente "tal como nos expressamos en tudo o que fazemos - seja ao ascender um cachimbo ou ao correr para apanhar um ônibus".

Simultaneamente ao neodassicismo, o espírito romântico jă se pronunciava, alto e em bom tom. Eugène Delacroix (1798-1863), expoente máximo da pintura romântica, pregava o predominio da cor sobre o descnho e jul ţava ser a maģinaçăo mais importante do gue o saber. Em sua obra, os contornos nítidos desaparecen e. dão lugar a cores exuberantes que ele havia descoberto em uma viagem ao Norte da África em 1832. Oterreno da tradição cedia mais um pouco, o que permite a Gombrich considerar o Romantismo como a primeira etapa de uma grande revoluçäo estética que marcatia o século XIX.

Se o primeino passo dessa revolução estética dizin respeito a cor, a segundo estaria relacionado ao tema e teria em Gustave Courbet (1819 1877) o precursor de uma pintura que não pretendia ser agradável mas que desvelasse a verdade, dando incio ao movimento Realista. Camponeses, homens comuns, situações cotidianas e tudo que parecia ofender os olhos da burguesia agora passavam a ser temas privilegiados desta pintura. Assim, a poética do movimento realista está relacionada as ideologias operárias que passăam a ocupar espaço importante no cenário histórico e político europeu. O próprio Courbet participon das barticadas de 1848 que pôs fim ao governo de Luís Filipe e instaurou a Segunda República na França, era o início da "primavera dos povos". Sua participaçăo no movimento contribuiu, de maneira inegável, para que ele repensasse acerca da participação da arte na realidade.

Contudo, se o realismo inovou no que diz respeito à temática, o mesmo não ocoreu quanto à forma de representar at tealidade. Os pintores realistas anda estavam "presos" aos ensinamentos da pintura acadêmica e, portanto, do ponto de vista estético, eram conservadores. Mais um passo foi necessário para, na opiniāo de Gombrich, a permanente revoluçăo estética do século XIX se consubstanciasse.

A terceira e última etapa dessa revolução teria se iniciado com Eduard Manet (1832-83) guando. em 1863 , teve suas obas recusadas ma exposiço oficial - o 
Salao dos Artistas Franceses. As consequientes agitaçôs levaram as autoridades a expor as obras negatas ne "Salăo dos Recusados". Nesse momento, ficou mats do que chara a divisäo entre pintores tradicionais, que näo questionavam o gosto oficial, o aqueles que buscavarn uma linguagem original. Manel e seas seguidores, os impressionistas, provocaram uma modificaçäo radical no gue diz respesto a reproduçio das cores. Descobriam que, ao contrário do que pensavan os pintores academicos. ao ar livre, natureza e objetos năo possuem uma cor propria mas uma mistura de matizes que se misturam em nossa mente. Os impressionistas alimentavam um total desinteresse pelo objeto representado, fixavam sua atençäo nos estudos sobre as sombras coloridas a a relaçüo entre as cores complementares. Tünam objetivos muito claros: apreender, atratvês da precepção imediata, o efêmero. Seus esforços consistiram muma tentativa deliberada de fundar a pintura sobre as leis clentfleas da visäo - a optica.

Enfim, a pintura tradicional teria despencalo no abismo. Nâo lavia mais uma tendencia a ser seguida mas a procura de soluções estéticas individuais. Encuanto os impressionistas queriam apreender a efemeridade das coisas a a fluidez das formas. Cézanne se preocupava em representar a solidez das mesmas no objetos; Paul Gaugin retomava a idéia roussoniana do bonz selvagem e partiu para o Tatiti em busca de una estếtica que conciliasse homem e natureza, de arn retomo aquilo que ê primordial, reaçüo pessoal as imposiçöes do mundo industrial.

Gaetan Picon, como o próprio nome de seu livro indica, 1863. Naissance de La peinture modome, especifica ma data para o momento de ruptura pois esta näo ocorreria por etapas, como pensava Gombrich. Para ele, se ế que é possivel especificar urn momento de ruptura, este momento seria o ano de $1863, \mathrm{com}$ o Saläo dos Recusados. E se anda tivesse que especificar um artista responsável por ola, este serva Exhard Manet com seu quadro intifulado Le dejaunersur I' herbe. Para Picon, este quadro marca ofim do imnginário coletivo, fim dos modelos de beleza, de ideais morais, fim do mundo como hierarquia. Fim, portanto, de alguns paradigmas e, consequentemente, surgimento do homem fragmentado, gue näo consegue restituir a

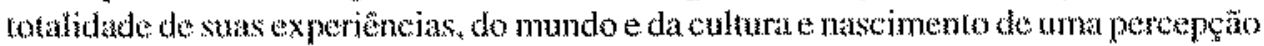

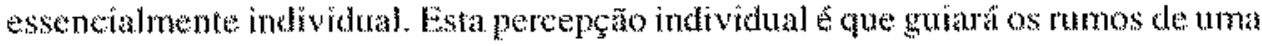
nova pintura, de uma nova arte.

A opiniäo de Jorge Coli no atigo Manet: o enigma do alhat, vem confirmat a importancia daste pintor para a modernidade. Ao se referir no texto do poeta $\mathrm{e}$ crítico Charles Baudelaire, O pintor da vida moderna, ele contraria a opiniäo deste que coma o pintor e gravador Consuntin Guys como aguele que funda a modermidade na pintura. No decorrer do texto, Coli destacal as características que larnam Maner o verdadero pintor da vida moderna: o seu poder de síntese, capaz de associar imagens de orgem diversas mas que säo completamente renovadas; a presença da cor negra, já constatada por Bandelaire como a cor da modernidade, que se apresenta näo mais na funça de figarar a sombra mas sim como elemento constitutivo comum a todas 
as cores; o processo rigoroso de composição onde volumes e modelados são radicalmente simplificados; sua resistência às tentações impressionistas em privilegiar a relação da natureza com a atmosfera, pois para ele é o ser humano que o interessa e a atualidade da sua temática, o mundo da moda, da elegância mas também da prostituição. O olhar de Manet é desprovido de memória, de história, traduz a impossibilidade de compreensão de um mundo que se tornou um enigma.

Na verdade, se o nascimento da pintura moderna começou com o romantismo histórico de Delacroix ou com Manet importa menos do que o fato de que a pintura moderna é o sintoma de um novo mundo onde o homem não se percebe mais enquanto sujeito histórico mas sim como mais um, entre tantos, fragmento que compõe o quadro da modernidade.

\begin{abstract}
:
The History of Art don't is a history by progress aplications of esthetic principles, on the contrary, is the break report of esthetics values and social-cultural. The birth of modern Art represent a radical rupture of esthetics values that had been origin in Renaissance, what permit us to considers the happens connected by the worlds of arts, in the second half of XIX century as a "esthetic revolution". Revolution this is that put an end to the imaginary collective, to models of beauty, to a conception of hicrarchied world and did to arise a perception essencially individual.
\end{abstract}

Keywords:

History, history of art, history of culture, esthetic.

\title{
Referências bibliográficas:
}

ARGAN, G. C. Arte moderna. São Paulo: Cia das Letras, 1993.

BAUDELAIRE, C. O pintor da vida moderna. In:

A modernidade de Baudelaire. Rio de Janeiro: Paz e Terra, 1988.

COLI, J. Manet. O enigma do olhar. In: AGUIAR, F. et al. O olhar. São Paulo: Cia das Letras, 1988.

FRANCASTEL, P. A realidade figurativa. São Paulo: Perspectiva e EDUSP, 1973. GOMBRICH, E. H. A história da arte. Rio de Janeiro: Guanabara, 1988.

PICON, G. 1863. Le naissance de la peinture moderne. Paris: Gallimard, 1996. 